\title{
A INEXPRESSIVA REPRESENTAÇÃO FEMININA NAS ACADEMIAS CIENTÍFICAS BRASILEIRAS E NO PRÊMIO NOBEL
}

\section{Resumo}

O texto trata da persistente quase ausência de mulheres nas principais academias científicas do Brasil e também entre os vencedores do Prêmio Nobel, e como tal fato ajuda a desestimular que alunas ingressem nas carreiras científicas, pois, inconscientemente, essas instituições passam a ideia de que a ciência é masculina. Argumenta-se que a maior inserção de mulheres nessas instituições, assim como a maior divulgação de mulheres cientistas, encorajaria que mais estudantes do sexo feminino se interessassem pelas carreiras acadêmicas. A título de ilustração, são apresentados dados referentes às principais academias científicas brasileiras, ao percentual de líderes de área na Coordenação de Aperfeiçoamento de Pessoal de Nível Superior (CAPES) do Brasil e ao Prêmio Nobel.

Palavras-chave: Mulheres cientistas, teoria do reconhecimento, Academias de Ciência do Brasil, Prêmio Nobel.

\begin{abstract}
The inexpressive feminine representation in the Brazilian scientific academies and in the Nobel prize

The text deals about the persistent and almost absence of women in the main scientific academies of Brazil and among the winners of the Nobel Prize and how this helps to discourage female students entering scientific careers since, unconsciously, these institutions convey the idea that science is masculine. It is argued that a greater insertion of women in these institutions, as well as a greater dissemination of female scientists, would encourage more female students to become interested in academic careers. As illustration, some data are presented referring to the main Brazilian scientific academies, to the percentage of area leaders in the Brazilian institution that awards grants for higher education (CAPES) and to the Nobel Prize.
\end{abstract}

Keywords: Women scientists, theory recognition, Brazilian Scientific Academies, Nobel Prize.

Faculdade FEAD, Belo Horizonte, Brasil

Endereço postal: Faculdade FEAD, Av. do Contorno 11.190 Centro, Belo Horizonte - MG, 30.110078, Brasil.

Endereço eletrónico: marcel.fae.ufmg@gmail.com

Faculdade de Direito de Contagem, Minas Gerais, Brasil

Endereço postal: Faculdade de Direito de Contagem, R. Papa Paulo VI, 39 - Inconfidentes, Contagem - MG, 32260-370, Brasil

Endereço eletrónico: godinhoprofessor@gmail.com 


\begin{abstract}
Resumen
La inexpresiva representación femenina en las academias científicas brasileñas y en el premio Nobel

El texto trata de la persistente casi ausencia de mujeres en las principales academias científicas de Brasil y también entre los vencedores del Premio Nobel, y como tal hecho ayuda a desestimular que alumnas ingresen en las carreras científicas, ya que, inconscientemente, esas instituciones pasan la idea de que la ciencia es masculina. Se argumenta que la mayor inserción de mujeres en esas instituciones, así como más divulgación de mujeres científicas, alentaría a que más estudiantes del sexo femenino se interesaran por las carreras académicas. Como ejemplificación, se presentan datos concernientes a las más importantes academias científicas brasileñas, al porcentaje de líderes de área en la institución brasileña responsable por la concesión de becas de enseñanza superior (CAPES) y al Premio Nobel.
\end{abstract}

Palabras clave: Mujeres científicas, teoría del reconocimiento, Academias de Ciencia de Brasil, Premio Nobel.

\title{
Introdução
}

Ao longo da história, o sexo feminino em geral permaneceu alijado do livre pensamento e as mulheres que ousaram transgredir esta discriminação, via de regra, eram condenadas à morte, ao isolamento ou à loucura. Aristóteles, ícone do saber ocidental, já afirmava na Grécia Antiga: «o macho é, por natureza, superior e a fêmea inferior». Durante a Inquisição medieval, chamadas de feiticeiras, as mulheres insubmissas eram excluídas da sociedade e, em inúmeros casos, queimadas vivas. Ao contrário, os homens que levavam a cabo os primeiros passos da ciência tal qual se conhece hoje eram vistos como sábios, enquanto a curiosidade e inteligência na mulher eram vistos como atributos demoníacos.

Sob o Iluminismo, a Revolução Francesa não cogitava que seus ideais, liberté, égalité, fraternité, também devessem ser estendidos ao sexo feminino. No século XIX, o psicólogo positivista Gustave Le Bon afirmou que «nas raças mais inteligentes, como é o caso dos parisienses, existe um grande número de mulheres cujo cérebro se aproxima mais em tamanho ao dos gorilas que ao dos homens» (Charyton et al. 2011, 204). Para a maioria dos pensadores da época, tal inferioridade era óbvia e incontestável, e Le Bon continuava: «sem dúvida existem algumas mulheres que se destacam [...], mas são tão excepcionais quanto o aparecimento de qualquer monstruosidade» (Charyton et al. 2011, 205).

Atualmente a situação se alterou bastante. Mulheres não enfrentam mais barreiras legais no acesso à educação, mas isso não significa que não existam impedimentos na inclusão feminina na educação, especialmente no nível superior. No campo científico ainda vigora a visão de que as ciências exatas são de domínio masculino e há toda uma hierarquia simbólica e burocrática não oficial nas relações de poder de gênero dentro dessas áreas. De fato, apesar da grande porcentagem de mulheres no ensino superior, poucas delas estão nas engenharias, na Física e na Matemática, por exemplo. Assim, as intelectuais que ingressam nessas áreas 
são sujeitas a visões estereotipadas do que é um profissional da ciência (Melo e Oliveira 2006).

Diante disso, neste texto discorre-se sobre o inexpressivo número de mulheres membros das academias científicas no Brasil, desde a fundação dessas primeiras instituições, e sobre alguns aspectos da Teoria do Reconhecimento de Axel Honneth pertinente à temática (Sobottka e Saavedra 2008). Ademais, são trazidos números referentes à participação feminina entre os líderes de uma importante agência federal de fomento de pesquisa (CAPES) e também estatísticas simples de sexo no prêmio Nobel, que aponta que tal fenômeno de segregação não se restringe ao Brasil.

\section{Mulheres nas academias de ciências e na CAPES}

Melo e Casemiro (2003) apresentam sua contribuição para essa temática fazendo a análise da participação de mulheres em duas importantes academias científicas nacionais: a Academia Brasileira de Ciências (ABC) e a Academia Nacional de Medicina (ANM). As autoras salientam que o maior acesso à educação não significa necessariamente maiores salários e acesso aos postos de poder para o sexo feminino. Pelo contrário, apesar de as mulheres chegarem em maior número ao ensino superior, elas ainda recebem menos pelas mesmas funções, têm que lidar com uma jornada dupla de trabalho e não estão suficientemente presentes nos sistemas políticos e sociais de poder científicos. Tal ilação das autoras se mostra atual tendo-se em vista os dados referentes aos líderes de área por grupo de sexo na Coordenação de Aperfeiçoamento de Pessoal de Nível Superior (CAPES), do Ministério da Educação do Brasil, conforme é mostrado mais adiante neste texto.

No entendimento desse problema, as pesquisadoras utilizam o conceito de gênero. Segundo a ótica das relações de gênero, as diferenças entre homens e mulheres não são de origem biológica, mas de caráter histórico, social e cultural, se firmando na desigualdade da distribuição de poder entre ambos. Com isso, mulheres em geral estão ausentes das esferas de tomada de decisão de ordem coletiva que interferem na dinâmica social. Tais padrões, num movimento de perpetuação desse modelo patriarcal, reafirmam sistemas históricos que determinam papéis assimétricos entre os sexos. Portanto, «gênero não é o mesmo que sexo. Sexo refere-se a uma condição biológica, diferente de se comportar de acordo com um modelo restrito de masculinidade ou de feminilidade» (Teixeira 2010, 85).

O mundo científico e tecnológico não é uma exceção a essa lógica generificada. A educação só atingiu um caráter universal no século XX, até então as mulheres eram analfabetas em sua maioria e estavam restritas ao ambiente doméstico. A ciência, por sua vez, alcançou progressos impressionantes nos últimos duzentos anos, mas esses avanços sempre foram associados a conquistas masculinas. É sob o peso desse argumento que Melo e Casemiro (2003) analisam as trajetórias dessas 
duas academias científicas (ABC e ANM) e estudam a ausência histórica e persistente de mulheres em sua composição.

É indiscutível que a crescente inclusão de mulheres no mercado de trabalho foi seguida pela ampliação de sua inserção nas instituições de ensino superior. Esperar-se-ia que, com a ampla participação numérica da mulher no ensino superior, essa inclusão se refletisse também nos centros produtores de ciência e de tecnologia no Brasil (Melo e Casemiro 2003). Contudo, apenas a inserção macroestrutural das mulheres não vem se mostrando suficiente para que um maior número delas atinja postos de liderança em pesquisas ou desempenhe poder nas instituições. Tal sub-representatividade também pode estar vinculada ao surgimento da autoconfiança no sujeito, que começa nos primeiros anos de vida, sendo a base sobre a qual se edificam as relações sociais entre indivíduos adultos, conforme a Teoria do Reconhecimento de Axel Honneth, que

vai além e sustenta que o nível de reconhecimento do amor-próprio é o núcleo fundamental de toda a moralidade [...], portanto, este tipo de reconhecimento é responsável não só pelo desenvolvimento do auto-respeito, mas também pela base de autonomia necessária para a participação na vida pública. (Sobottka e Saavedra 2008, 11)

Desta maneira, sob o ponto de vista das identidades subjetivas, o exíguo número de cientistas mulheres que integram as academias científicas advém de dois fenômenos psicoculturais interconexos: 1. por um lado elas ainda não são vistas, por seus pares masculinos, totalmente como iguais, por mais que os discursos oficiais e institucionais verbalizem o contrário; 2 . correlativamente, esses e outros fatores fazem com que, no imaginário feminino, inclusive das cientistas, elas rejeitem se inserir em tais associações porque não se reconhecem como legítimas representantes de tais instituições, ou então, em decorrência do modo como foram educadas (menos competitivas, menos «agressivas») não coadunam com alguns preceitos e valores «bélicos» pertinentes a tais agremiações.

Logo, recuperar a memória e a trajetória dos nomes das mulheres nas ciências brasileiras não só fortalece a identidade feminina, mas também estimula as novas gerações a se guiar por exemplos positivos (Melo e Casemiro 2003). Isso porque, em geral, quando se pronuncia a palavra cientista, a primeira representação imagética que vem à mente das pessoas é de um indivíduo do sexo masculino, idade avançada, branco (europeu ou norte-americano) e com a aparência tresloucada (Chassot 2003). Por esse motivo, abordar a invisibilidade das mulheres que fizeram carreiras dentro daquelas é uma forma de combater a discriminação feminina nas ciências.

O trabalho de Melo e Casemiro (2003) utilizado neste artigo não esgota a discussão sobre o tema estudado e nem é fonte única de embasamento empírico deste artigo. $\mathrm{O}$ que se buscou foi, com base no texto das autoras, apresentar uma tendência existente na cultura brasileira de subjugação feminina no campo das 
ciências, o que ao longo do trabalho vai sendo discutido com a literatura atual que trata sobre questões de gênero, patriarcado e outras afetas ao trabalho, além de apresentar dados obtidos junto à Coordenação de Aperfeiçoamento de Pessoal de Nível Superior (CAPES) e ao Prêmio Nobel, demonstrando que, assim como no trabalho das autoras no ano de 2003, atualmente as mulheres ainda permanecem como minoria nestas áreas.

\section{Academia Nacional de Medicina}

A Academia Nacional de Medicina (ANM) foi fundada em 1829, sendo uma das mais antigas instituições científicas do Brasil. Originalmente Sociedade de Medicina do Rio de Janeiro, tinha o objetivo de agenciar o aperfeiçoamento da prática médica no país. Em 1835, a instituição ganha o título de instituição oficial do Império e se torna a Academia Imperial de Medicina (Paulino Netto, Porto, e Santos 2004). De início funcionou no histórico edifício em estilo neoclássico da Santa Casa de Misericórdia do Rio de Janeiro, sendo presidida pelo médico-cirurgião Joaquim Cândido Soares de Meirelles. A primeira sessão oficial aconteceu em 1830 com a presença do Imperador D. Pedro I, que compareceria recorrentemente em diversas ocasiões posteriores. Anualmente, desde 1831, publica a revista Anais da Academia Nacional de Medicina, o periódico científico mais antigo em atividade no Brasil.

Foi somente com a proclamação da República, em 1889, que a instituição ganhou o título de Academia Nacional de Medicina. Esta, de acordo com o seu estatuto, tem um número fixo de sócios, cem Membros Titulares, e um número não fixo de Membros Eméritos e de Membros Honorários (nacionais e estrangeiros). No período da fundação da instituição, mulheres não frequentavam faculdades no Brasil. Suas pioneiras só foram aceitas nestes espaços a partir do ano de 1879, sendo as faculdades da Bahia e do Rio de Janeiro as primeiras a admitir alunas no curso de Medicina (Melo e Casemiro 2003).

A primeira mulher membro da Academia Nacional de Medicina foi a francesa naturalizada brasileira Maria Josephine Mathilde Durocher (1802-1893), parteira licenciada pela Faculdade de Medicina do Rio de Janeiro e a primeira mulher a assinar textos científicos na área médica no país. Praticou durante sessenta anos uma ocupação habitualmente atribuída às mulheres, a de parteira. $\mathrm{O}$ ofício era visto somente como uma extensão das funções que as mulheres já possuíam, como a reprodução e o cuidado com as crianças. A Medicina oficial via as parteiras como despreparadas e incapazes, mas estas realizavam a maioria dos partos e ainda eram responsáveis pelos cuidados com a saúde da mulher.

Durocher era encarada como uma praticante excepcional do seu ofício, mas, mesmo assim, sua admissão na ANM foi vista com desconfiança por alguns. Apesar disso, foi nomeada membro adjunto em 1871 e membro titular em 1885. 
A cientista Marie Curie (1867-1934) foi a segunda mulher a receber o título de membro da Academia Brasileira de Medicina. Em sua visita ao Brasil, em 1926, recebeu também o título na Academia Brasileira de Ciências. A homenagem era um esforço no caminho de promover a ciência no Brasil. A terceira mulher eleita, em 1942, foi a médica e deputada federal paulistana Carlota Pereira de Queiroz (1892-1982).

Estas três pioneiras só tiveram uma sucessora em 1971, a quarta mulher eleita, Gertrudes Meissner, membro honorário estrangeiro. Depois dela, dez anos se passaram para que a quinta mulher fosse eleita: a médica carioca Maria Brasília Leme Lopes (Melo e Casemiro 2003). Quando as autoras escreveram o artigo, a Academia de Medicina contava com quatro médicas: Léa Ferreira Camilo-Coura, Anna Lydia Pinho do Amaral, Anadil Vieira Roselli e Talita Romero Franco. Apenas estas e as cinco já citadas compunham todo o quadro de mulheres membros dessa Academia até 2003.

Tal constatação confirma que não resolve o problema da discriminação sexual apenas que, numericamente, mais mulheres ingressem nos cursos superiores para que mais alunas se interessem pela ciência, pois, e o caso da Medicina é típico, elas estão praticamente pari passu com os homens em relação ao alunado de graduação e de bacharéis na área, no entanto, a representatividade das mulheres nesse campo científico ainda está aquém e as que se introduzem nessa área científica têm menores oportunidades de acesso. Talvez uma das explicações para esse fato seja o não reconhecimento (tácito, implícito e inconsciente) e, no extremo, o preconceito e a discriminação da sociedade em relação às mulheres no fazer da ciência, mecanismo este que é mais bem entendido à luz do Interacionismo Simbólico:

A identidade é atribuída pela sociedade, mas é preciso que o contexto social assegure sua manutenção, à medida que as outras pessoas estejam dispostas a reconhecer o sujeito como aquela pessoa que ele está sendo (aquela identidade). Cada vez que o indivíduo se liga a pessoas que sustentam suas auto-interpretações, ele confirma sua identidade. [...] É nessa perspectiva que o papel do preconceito precisa ser analisado - uma séria consequência do preconceito é fazer com que o indivíduo se torne aquilo que a imagem preconceituosa afirma que ele é. (Goulart e Bregunci 1990, 56)

Também é interessante destacar que em seus primórdios houve um negro (seria «mulato» no linguajar do senso comum) entre seus primeiros presidentes, tendo tido quatro mandatos (não sequenciais) entre 1829 e 1848, enquanto nenhuma mulher foi presidente desta academia até o presente momento. Quanto ao número atual de membros do sexo feminino, 5 (cinco), representam exíguos 5\% dos 100 membros titulares e eméritos, e são elas: Eliete Bouskela, Lea Ferreira Camilo Coura, Mônica Roberta Gadelha, Patrícia Rieken Macedo Rocco, Talita Romero Franco (ANM 2016). 


\section{Academia Brasileira de Ciências}

A partir dos anos 1990, o Brasil presenciou grande avanço nos seus índices de escolarização, seja pelos fatores de uma vida escolar mais longa ou porque houve mais vagas em universidades; as mulheres se viram no cerne desse progresso de ampliação da escolarização superior. Atualmente, elas estão em maior número nas instituições universitárias e disputam com os homens pelos mesmos postos de trabalho. Contudo, o universo escolar e o profissional ainda são distintos para ambos os sexos. Há carreiras vistas como tradicionalmente femininas e há carreiras encaradas como tipicamente masculinas. A composição da Academia Brasileira de Ciências é característica deste fenômeno de caráter cultural e também socioeconômico.

A Academia Brasileira de Ciências (ABC) foi fundada em 1919, também no Rio de Janeiro, com o título original de Sociedade Brasileira de Ciências. Recebeu em 1921 a sua atual denominação e consta em seu estatuto o objetivo de «contribuir para o desenvolvimento da Ciência e Tecnologia, da educação e do bem-estar do país» (Melo e Casemiro 2003, 123). A composição atual da Academia consta com dez seções (áreas): Ciências Matemáticas, Ciências Físicas, Ciências Químicas, Ciências Biológicas, Ciências Biomédicas, Ciências da Saúde, Ciências Agrárias, Ciências da Engenharia e Ciências Humanas. Os membros permanentes são divididos em três categorias: Titulares, Estrangeiros e Colaboradores. De caráter temporário existe o posto de Membro Institucional, aberto a pessoas jurídicas.

Quando da publicação do artigo de Melo e Casemiro (2003), dos 571 sócios da $A B C$, apenas 56 eram mulheres (9,8\%). Do número geral de membros, $58 \%$ deles são membros titulares, o posto com maior reconhecimento dentro da instituição. A participação feminina nesses postos mais altos era de apenas 7,8\%. Tal fato demonstra como ainda é pequeno o reconhecimento do papel da mulher nas áreas de Ciência e de Tecnologia (Melo e Casemiro 2003).

Comprovando o peso do campo da biomedicina para a ciência nacional, é observado que a maioria dos acadêmicos e acadêmicas da $A B C$ está concentrada nessa área. Dentre a parcela feminina da Academia, a superioridade nas ciências biomédicas é mais elevada. As acadêmicas dessa área correspondiam, àquela época, a 35,7\% do total de membros do sexo feminino, o que confirma a feminização crescente dessa área, o mesmo ocorrendo com as ciências químicas e biológicas. Já nas seções de Ciências de Saúde, Ciências Agrárias e Ciências da Engenharia, a participação feminina era nula em 2003, sendo que, com exceção do campo da saúde, as duas últimas são áreas tradicionalmente masculinas, possuindo ainda obstáculos simbólicos e psicológicos para a entrada das mulheres.

Apesar dessa situação, representando alteração mais recente no quadro da ABC, a partir de 2001, a seção de Ciências Humanas abriu as portas para a entrada de um maior número de mulheres na Academia. Na seção de Ciências Humanas a participação das mulheres é mais proporcional, visto que elas representam um 
terço do total. Melo e Casemiro (2003) atribuem essa forte presença ao fato de o estudo das Humanidades ainda ser visto pela sociedade como um dos atributos próximos dos atributos considerados femininos: a docilidade e a interação com o outro.

O avanço também se refletiu no quadro geral de membros da $\mathrm{ABC}$, mas a participação feminina ainda é mínima. São 1009 homens e só 66 mulheres na história da Academia Brasileira de Ciências no século XX. Ainda na década de 1990 a taxa de crescimento da participação feminina foi de 106\%. Mesmo assim, a ABC ainda pode ser considerada um espaço masculino, pois somente $6,5 \%$ dos acadêmicos eram mulheres em 2003 e havia áreas em que não havia nenhuma representante (Melo e Casemiro 2003).

Hoje em dia, a distribuição de mulheres nas distintas áreas científicas da $\mathrm{ABC}$, a partir da que tem menor percentual de mulheres para a que tem mais, é a seguinte, ressaltando que as áreas de Ciências da Terra e Agrárias foram aglutinadas assim como as áreas de Ciências da Saúde e Biomédicas (ABC 2016):

Tabela 1.

Percentual de mulheres e de homens por área de conhecimento na $\mathrm{ABC}$

\begin{tabular}{lccccc}
\hline \multicolumn{1}{c}{ Área } & Feminino & Masculino & $\% \mathbf{F}$ & $\% \mathbf{~ M}$ & Total \\
\hline Matemática & 5 & 105 & 4,50 & 95,50 & 110 \\
Física & 9 & 135 & 6,25 & 93,75 & 144 \\
Engenharias & 4 & 56 & 6,67 & 93,33 & 60 \\
Agrárias e da Terra & 12 & 104 & 10,34 & 89,66 & 116 \\
Química & 19 & 88 & 17,76 & 82,24 & 107 \\
Saúde e Biomédicas & 41 & 183 & 18,30 & 81,70 & 224 \\
Ciências Sociais & 6 & 24 & 20,00 & 80,00 & 30 \\
Biológicas & 25 & 98 & 20,33 & 79,67 & 123 \\
Geral ABC & 121 & 793 & 13,24 & 86,76 & 914 \\
\hline
\end{tabular}

Fonte: Academia Brasileira de Ciências (ABC 2016).

No que tange à história da mulher na Academia, a primeira mulher a receber um título, dez anos depois da criação da instituição, foi Madame Curie em 1926. No mesmo ano foi homenageada uma cientista alemã, mas que trabalhava no Brasil: a doutora Maria Emilie Snethlage. Naturalista e diretora do Museu do Pará, seus estudos sobre aves brasileiras prestaram grande contribuição para a história natural do país. Somente dez anos depois a Academia elegeu outra mulher, a norte-americana naturalizada brasileira Carlota Joaquina de Paiva Maury, paleontóloga. Todas as três, no entanto, foram eleitas para um posto intermediário, o de membro correspondente.

Diante disso, pode-se considerar que, genuinamente, a primeira brasileira a ser eleita membro da ABC foi a Professora Marília Chaves Peixoto, como Membro 
Associado na seção de Ciências Matemáticas em 1951. Em seguida, na década de 1960, foi Martha Vannucci, uma zoóloga, professora da Universidade de São Paulo.

A questão seguinte trazida por Melo e Casemiro (2003) é a notável concentração na região Sudeste do Brasil de acadêmicos eleitos. Sendo uma instituição nacional, a $\mathrm{ABC}$ deveria abranger mais igualmente todo o território nacional. Não é o que se observa. A distribuição desigual de recursos no sistema universitário e o consequente desenvolvimento científico e tecnológico que o segue revelam um quadro que confirma o padrão geral da distribuição do PIB nacional. Na região Sudeste, trabalham $89 \%$ das acadêmicas eleitas. A grande maioria delas é docente em universidades públicas, tais como UFRJ (com 15 representantes) e USP (com 11 membros).

O artigo de Melo e Casemiro (2003) ainda analisa estrutura de poder vigente na $A B C$. Observa-se que as mulheres têm uma taxa de participação muito reduzida quando comparada com sua participação nos postos de liderança dos Grupos de Pesquisa do CNPq. Somente uma mulher participou da direção da Academia Brasileira de Ciências na sua história, a cientista Johanna Döbereiner. Engenheira agrônoma de origem alemã, a doutora Döbereiner foi umas das mais importantes cientistas do Brasil, indicada ao prêmio Nobel de Química em 1997 pelos seus estudos para o desenvolvimento da cultura da soja.

Interessante é constatar que, no imaginário coletivo se atribui, ainda que indiretamente, a falta de mulheres nas academias científicas à própria mulher, ou seja, à sua extrema modéstia e/ou baixa autoestima profissional, processo que fica evidente quando as autoras citam o discurso do presidente da Academia Nacional de Medicina na posse da doutora Anadil Vieira Roseli: «Outras colegas existem com méritos para se tornarem acadêmicas. O que lhes falta é o desejo de se apresentarem. Que o façam» (Melo e Casemiro 2003, 121).

O problema desses argumentos é que, quando se assume que a questão se restringe ao desejo das mulheres, não se consideram fatores culturais e micropolíticos que continuam criando barreiras invisíveis para a participação das mulheres e que, para destruir essas barreiras, é necessária determinação política e mudanças na mentalidade social. A ascensão das mulheres nas ciências médicas é ilustrativa da Teoria do Reconhecimento já aludida, não obstante ainda existam menos mulheres desenvolvendo pesquisas nesse campo e, sobretudo, exercendo poder em tal campo se comparadas aos homens.

De fato, em termos numéricos e de conquista de legitimidade, a Teoria do Reconhecimento explica, em parte, o que sucedeu nesta área em relação à diminuição do estigma que cerceia a mulher nas ciências naturais:

Assim que a tradição hierárquica de valoração social, progressivamente, vai sendo dissolvida, as formas individuais de desempenho começam a ser reconhecidas. Honneth parte do princípio de que uma pessoa desenvolve a capacidade de sentir-se valorizada somente quando suas capacidades individuais não são mais avaliadas de forma coletivista (Sobottka e Saavedra 2008, 13). 


\section{Coordenação de Aperfeiçoamento de Pessoal de Nível Superior (CAPES)}

Outro dado que merece destaque é a reduzida participação feminina nas coordenações das Grandes Áreas da Coordenação de Aperfeiçoamento de Pessoal de Nível Superior (CAPES). Nestas áreas constata-se que 79,59\% são coordenadores, enquanto apenas 20,41\% são coordenadoras. Neste mesmo sentido, 59,18\% são coordenadores adjuntos (vice), enquanto somente $40,82 \%$ são coordenadoras adjuntas (CAPES 2017). Isso indica que, diferentemente do que prega a meritocracia, não são apenas questões ligadas à capacitação formal dos indivíduos os únicos fatores a fazer com que eles avancem ou não na carreira profissional, já que, ao se passar de um nível mais alto ao mais inferior - coordenação titular para coordenação adjunta -, o percentual feminino da CAPES aumenta, fenômeno esse que se dá, sistematicamente, em todas as grandes áreas do conhecimento: Ciências Exatas, Agrárias e da Terra, da Saúde, Ciências Humanas, Letras e Artes, Ciências Sociais Aplicadas e Ciências Biológicas.

Percebe-se, a partir dos resultados apresentados na pesquisa de Melo e Casemiro (2003), que ainda se mantém a mesma lógica discriminatória de gênero, ou seja, que há a predominância de homens nas funções de maior destaque nas ciências. É importante destacar que embora os homens ainda sejam a maioria presente nestas áreas, houve uma mudança considerável neste cenário, uma vez que a diferença entre homens e mulheres se vem reduzindo em termos percentuais. Embora haja esta diminuição nas diferenças entre homens e mulheres, estes números estão longe de se tornar aceitáveis quando se considera que o número de mulheres que ingressam no ensino superior vem cada vez mais aumentando (Teixeira e Freitas 2017).

\section{Mulheres e Prêmio Nobel}

Em relação ao Prêmio Nobel, e desconsiderando-se os prêmios relativos à Paz e à Literatura, já que não se configuram como campos científicos, a distribuição por sexo ao longo do tempo foi a seguinte até os dias de hoje:

Tabela 2.

Percentual de homens e de mulheres vencedores do Nobel por área de conhecimento

\begin{tabular}{lccccc}
\hline \multicolumn{1}{c}{ Área } & Feminino & Masculino & $\% \mathbf{F}$ & $\% \mathbf{M}$ & Total \\
\hline Física & 2 & 199 & 0,99 & 99,01 & 201 \\
Química & 2 & 170 & 1,16 & 98,84 & 172 \\
Medicina e Fisiologia & 12 & 198 & 5,71 & 94,29 & 210 \\
Economia & 1 & 75 & 1,31 & 98,69 & 76 \\
\hline
\end{tabular}

Fonte: Nobel Prize (2016). 
Somando-se todos os prêmios Nobel até hoje concedidos, incluindo-se o Nobel da Paz e Nobel de Literatura, os números são ainda mais fortemente desfavoráveis ao sexo feminino pois, dentre um total de 851 prêmios, apenas 44 foram entregues a mulheres, que perfazem um exíguo total de 5,17\%. Um fato interessante, mas pouquíssimo conhecido, é que Marie Curie foi a única pessoa até hoje a receber prêmios em duas categorias diferentes, no caso, em Física e em Química (Charyton et al. 2011).

\section{Conclusões}

É indubitável que a sociedade se modificou e milhares de mulheres começaram a ocupar espaços antes monopólios masculinos, como é o caso dos esportes, da política, das forças armadas, da ciência. No entanto, se hoje já são vistos muitos casos positivos, proporcionalmente à fatia que representam da população, a inserção das mulheres nesses campos ainda é injusta. Além disso, muitas das que enveredam pelo campo científico, para não atrair o assédio sexual ou para enfrentar o preconceito, abrem mão de sua feminilidade, transformando-se num pastiche de homem, adotando o que a sociedade estipula como condutas masculinas (Chassot 2003).

Ademais, ainda persistem na sociedade, desde o ensino fundamental até o universitário, passando pela mídia, sólidos estereótipos concernentes ao que é um cientista «legítimo» - homem, branco, com cabelo desgrenhado, impaciente e com óculos de lentes grossas - ao mesmo tempo em que não são difundidos exemplos positivos de mulheres que tenham se destacado nas ciências. O estereótipo do sexo feminino como um ser frágil contribui para cercear as discentes ao campo das humanidades, das artes e, na melhor das hipóteses, nas ciências naturais, à área da saúde - Enfermagem, Odontologia, Fisioterapia etc. -, visto que é recorrente a ausência de mulheres cientistas dentro da Medicina (haja vista que seus cursos de graduação apresentam quase paridade entre homens e mulheres), por exemplo.

Sendo assim, apesar da crescente escolarização das mulheres nas últimas décadas e do aumento da participação delas no mercado de trabalho, preconceitos e discriminações - hoje mais simbólicos e culturais do que jurídicos ou burocráticos - advindos da secular cultura patriarcal ainda desestimulam as mulheres a se inserir nos diferentes campos científicos e, uma vez dentro deles, as impedem de ascender na carreira tanto quanto os homens. Ao lado da dupla (ou tripla) jornada de trabalho, dos menores rendimentos por igual função e da sub-representatividade no sistema político, entre outros fatores, a inexpressiva participação das mulheres nas ciências naturais é outro indício de que estereótipos de gênero até o presente atuam fortemente na sociedade.

Mesmo sendo inegável a grande participação das mulheres nas Ciências Humanas, Sociais e da Saúde é importante o esforço de identificar quem são as mulheres dos sistemas científicos e tecnológicos: além dos números, é importante 
conhecer suas trajetórias acadêmicas e biografias pessoais. Os valores que apregoam uma «natureza feminina», ligada a características como docilidade e submissão, fortalecem essas barreiras invisíveis que boicotam as formas de viver das mulheres. Elas recebem salários mais baixos, atuam mais comumente em setores de serviços e, na indústria, são mais encontradas nos ramos de manufatura (Leta 2003).

Com efeito, o esforço na direção de analisar o fenômeno da baixa participação das mulheres nas áreas científicas e tecnológicas é um primeiro passo para incentivar mais mulheres a adotar uma carreira científica em campos tradicionalmente ocupados por homens. É com essa intenção que é relevante o estudo da (ainda pequena) participação feminina nas Academias de Medicina e Ciências. Sendo assim, as mulheres, enquanto grupo, só galgarão melhores e mais postos significativos nas ciências naturais, principalmente nas ciências exatas e da terra, quando o sexo feminino for visto não como inferior ou igual mas como equivalente ao masculino.

De acordo com Sobottka e Saavedra (2008), a solidariedade na sociedade moderna está vinculada à condição de relações sociais simétricas de estima entre indivíduos autônomos e à possibilidade de os indivíduos desenvolverem a sua autorrealização. Para que os atores sociais possam desenvolver um autorrelacionamento positivo e saudável, eles precisam ter a chance simétrica de desenvolverem a sua concepção de boa vida sem sofrerem os sintomas das patologias oriundas das experiências de desrespeito, é justamente o respeito e a isonomia que se espera entre homens e mulheres.

Relativamente ao Prêmio Nobel, a exígua percentagem de mulheres agraciadas com esse laurel se coaduna com os parcos índices de representação feminina nas academias científicas brasileiras, embora esses índices estejam aumentando lentamente, tanto nacional quanto internacionalmente, o que demonstra a exigência urgente de políticas públicas em educação voltadas à equiparação entre os sexos, assim como vem sendo feito no Brasil, por exemplo, concernente à questão racial com os programas denominados Ações Afirmativas para a inclusão de mais negros, indígenas e seus descendentes no ensino superior e nas ciências.

O que se pode deduzir com base nos dados que foram apresentados são as manifestas coerções invisíveis que ainda acontecem no meio acadêmico e que acabam desestimulando que mulheres avancem nas ciências. O caso dos líderes de área da CAPES também é emblemático ao apontar que relações de poder atravessam o fazer científico. Este não diz respeito somente a questões técnicas, de formação e de habilidades, visto que em todas as grandes áreas o número de líderes mulheres é menor que o de líderes homens e quando se desce na questão hierárquica (coordenação adjunta) se nota que o percentual feminino é um pouco superior, porém, também aí não é proporcional ao percentual de homens.

A permanência de comportamentos androcêntricos baseados no histórico patriarcado ainda relega as mulheres para funções coadjuvantes nas ciências. De acordo com dados recentes levantados na Universidade Federal de Minas Gerais, 
em seus cursos de graduação no ano de 2016, constatou-se que 52\% dos discentes dos cursos de graduação são mulheres, evidenciando que, mesmo havendo um maior número de mulheres ingressando no ensino superior, elas não mantêm a mesma progressão e participação percentual quando é analisado o número de mulheres cientistas (Teixeira e Freitas 2017), que compõem apenas 47\% do corpo docente dos cursos de pós-graduação desta instituição.

Sob a perspectiva das discriminações e tratamentos diferenciados entre mulheres e homens, conclui-se que a não adoção de medidas pontuais, como reformulação de políticas públicas e maior qualificação para os docentes, desde o ensino básico até o ensino superior, implica que as mulheres continuarão sendo vítimas deste «teto de vidro» que tende a manter os privilégios para os homens, deixando às mulheres sempre o papel secundário.

\section{Referências Bibliográficas}

ABC - Academia Brasileira de Ciências. 2016. Disponível em http://www.abc.org.br/centenario/. [Consultado em 23 de fevereiro de 2017].

ANM - Academia Nacional de Medicina. 2016. Disponível em http://www.anm.org.br/. [Consultado em 25 de fevereiro de 2017].

CAPES - Coordenação de Aperfeiçoamento de Pessoal de Nível Superior. 2017. Coordenadores de grande área. Disponível em http://www.capes.gov.br/. [Consultado em 1 de março de 2017].

Charyton, Christine, John O. Elliott, Mohammed A. Rahman, Jeness L. Woodard, Samantha DeDios. 2011. «Gender and science: women Nobel laureates». Journal of Creative Behavior 45 (3), 203-214. DOI: https://doi.org/10.1002/j.2162-6057.2011.tb01427.x

Chassot, Attico. 2003. A ciência é masculina? Porto Alegre: Editora Unisinos.

Goulart, Iris Barbosa, e Maria das Graças de Castro Bregunci. 1990. «Interacionismo simbólico: uma perspectiva psicossociológica». Revista em Aberto 9 (48): 50-60. Disponível em http://emaberto.inep.gov.br/index.php/emaberto/article/view/1791

Leta, Jacqueline. 2003. «As mulheres na ciência brasileira: crescimento, contrastes e um perfil de sucesso». Estudos Avançados 17 (49): 271-284. DOI: http://doi.org/10.1590/ S0103-40142003000300016

Melo, Hildete Pereira, e Maria Carolina Pereira Casemiro. 2003. «A ciência no feminino: uma análise da Academia Nacional de Medicina e da Academia Brasileira de Ciência». Revista Rio de Janeiro 11: 117-133. Disponível em http://www.forumrio.uerj.br/ documentos/revista_11/11-Hildete.pdf

Melo, Hildete Pereira, e André Barbosa Oliveira. 2006. "A produção científica brasileira no feminino». Cadernos Pagu 27, 301-331. DOI: https://doi.org/10.1590/S010483332006000200012

Nobel Prize. 2016. Nobelprize.org. Disponível em https://www.nobelprize.org/. [Consultado em 27 de fevereiro de 2017].

Paulino Netto, Augusto, Jarbas Porto, e Omar da Rosa Santos. 2004. «História da Academia Nacional de Medicina». Acta Medica Misericordiæ 7 (1): 7-10.

Sobottka, Emil Albert, e Giovani Agostini Saavedra. 2008. «Introdução à Teoria do Reconhecimento de Axel Honneth». Civitas 8 (1): 46-67. DOI: https://doi.org/10.15448/19847289.2008.1.4321 
Teixeira, Adla Betsaida Martins. 2010. «Distinção de Gênero e seus Reflexos na Rotina Escolar de Docentes e Discentes». In Temas Atuais em Didática, organizado por Adla Betsaida Martins Teixeira, 83-104. Belo Horizonte: Editora UFMG.

Teixeira, Adla Betsaida Martins, e Marcel de Almeida Freitas. 2017. «A sistêmica defasagem da participação feminina nas ciências». Trabalho apresentado na 69. ${ }^{a}$ Reunião Anual da Sociedade Brasileira para o Progresso da Ciência: Inovação, Diversidade, Transformações, 16 a 22 de julho, Universidade Federal de Minas Gerais, Belo Horizonte.

Marcel de Almeida Freitas. Sociólogo, Mestre em Psicologia. Doutorando em Educação na Faculdade de Educação da Universidade Federal de Minas Gerais (FaE/ UFMG). Professor na Faculdade FEAD, Belo Horizonte, Minas Gerais, Brasil.

Endereço eletrónico: marcel.fae.ufmg@gmail.com

Eduardo Godinho Pereira. Bacharel em Direito, Mestre em Administração de Empresas. Doutorando em Educação na Faculdade de Educação da Universidade Federal de Minas Gerais (FaE/UFMG). Professor na Faculdade de Direito de Contagem, Contagem, Minas Gerais, Brasil.

Endereço eletrónico: godinhoprofessor@gmail.com

Artigo recebido a 15 de maio de 2017 e aceite para publicação a 16 de outubro de 2017. 